\title{
PENGARUH PEMANFAATAN FILTER UDARA BERBAHAN ZEOLIT TERAKTIVASI FISIK MENGGUNAKAN Microwave TERHADAP AKSELERASI SEPEDA MOTOR BENSIN 4-LANGKAH
}

\author{
Tata Kurniawan', Herry Wardono ${ }^{1}$, dan M. Dyan Susila E.S. ${ }^{1}$, \\ 1) Jurusan Teknik Mesin, Fakultas Teknik Universitas Lampung \\ Jln. Prof.Sumantri Brojonegoro No. 1 Gedung H FT Lt. 2 Bandar Lampung \\ Telp. (0721) 3555519, Fax. (0721) 704947 \\ email : tatakuniawaan28@gmail.com.
}

\begin{abstract}
Atmospheric contains a variety of gases such as $78 \%$ nitrogen, $21 \%$ oxygen and 1\% other gases. This causes incomplete combustion. Because the main composition of the combustion process is fuel and oxygen. The use of zeolite physically activated by microwave which can increase the quality of combustion air. Zeolite is a type of rock that is capable of absorbing (capturing) molecular particles or angstroms such as water vapor and nitrogen in the air. So that it will produce a rich oxygen in the air when entering the combustion chamber. The performance of a 4-stroke motorcycle engine is good if there is a decrease in fuel consumption, it can increase the acceleration, and reduce exhaust emissions containing CO and UHC. To find out the effect of the zeolite filters on engine performance, an acceleration test of $0-80 \mathrm{~km} / \mathrm{h}$ is performed. Zeolite is activated using a microwave with $80 \%$ power, activation time is 3, 6, and 9 minutes, with gap of $75 \%$. Then zeolite was activated with $80 \%, 60 \%$, and $40 \%$ power of microwave using $50 \%$, 75\%, and 100\% gap (varying the gap arrangement of pellets). When the activation time of the filter is 3 minutes, it takes 12.54 seconds to conduct, $6.53 \%$ faster, the a 6 minutes activation takes 12.58 seconds and $6.19 \%$ faster. The greater the activation power, the better acceleration. In the $80 \%$ acceleration test, $50 \%$ gap can increase the acceleration by a percentage of $6.16 \%$. Meanwhile, the gap of $75 \%$ and $100 \%$ it can increase the acceleration by $5.64 \%$ and $3.86 \%$.
\end{abstract}

Keywords: Zeolite, physical activation, using microwave, increase acceleration.

\section{PENDAHULUAN}

Udara pada atmosfer bumi mengandung berbagai macam gas seperti nitrogen $78 \%$, oksigen $21 \%$ dan $1 \%$ lainya merupakan uap air [5]. Komposisi udara tersebut akan menyebabkan pembakaran tidak sempurna dalam proses pembakaran, komposisi utama proses pembakaran adalah bahan bakar dan oksigen. Oleh karena itu, apabila kandungan oksigen dalam proses pembakaran tersebut kurang maka pembakaran tidak sempurna sehingga tenaga pada sepeda motor berkurang dan menurunkan akselerasi mesin sepeda motor. Akan tetapi, permasalahan tersebut dapat dikurangi dengan cara pemanfaatan filter udara berbahan zeolit teraktivasi fisik microwave yang meningkatkan kualitas udara pembakaran.

Zeolit merupakan jenis batuan yang mampu mengadsorb (menangkap) partikel berukuran molecular atau angstrom seperti uap air dan nitrogen di udara [6]. Rongga zeolit berisi kation logam yang dapat ditukar, seperti: $\mathrm{Na}^{+}$, $\mathrm{K}^{+}, \mathrm{Ca}^{2+}, \mathrm{Mg}^{2+}$, serta dapat mengikat molekul lain [3]. Zeolit pertama kali diketahui oleh freiherr axer Frederick cronsteadt pada tahun 1756 yang merupakan ahli meneralogi dari Swedia. Zeolit berasal dari 2 kata yaitu Zein (mendidih) dan Lhitos (batuan) merupakan bahasa yunani, yang mempunyai arti batu mendidih, mengapa disebut batu mendidih karena apabila zeolit dipanaskan akan 
mendidih dan mengembang.

Sebelum dipakai untuk filter sepeda motor zeolit perlu diaktivasi untuk meningkatkan daya adsorbnya, yaitu dengan mengaktivasi secara fisik menggunakan microwave. Sehingga dengan mengontakkan udara pembakaran pada zeolit akan dihasilkan udara yang kaya oksigen. Prestasi mesin sepeda motor bensin 4 langkah dikatakan bagus apabila terjadi penurunan konsumsi bahan bakar, mampu meningkatkan akselerasi, dan mereduksi emisi gas buang yang mengandung CO dan UHC. Pengaruh penggunaan filter zeolit diaktivasi fisik terhadap prestasi mesin mobil bensin (EFI) 1600 cc. Penggunaaan filter zeolit teraktivasi fisik mampu meningkatkan 0,83 detik (7,29\%) dari kondisi tanpa zeolit [4]. Selain itu, filter zeolit fly ash aktivasi fisik mampu meningkatkan akselerasi sebesar $15,23 \%$ [2].

Adapun tujuan dilakukannya penelitian ini adalah untuk mengetahui pengaruh variasi waktu dan daya aktivasi fisik menggunakan microwave, serta mengetahui pengaruh variasi kerapatan pelet filter zeolit terhadap akselerasi sepeda motor mesin bensin 4- langkah.

\section{METODE PENELITIAN}

\section{Pembuatan Filter Zeolit}

Bahan yang digunakan untuk membuat filter zeolit antara lain zeolit, perekat (tepung tapioka), dan air mineral, sementara itu alat yang digunakan yaitu tumbukan, ayakan dengan ukuran mesh 100, timbangan, wajan, kompor, ampia, cetakan, kawat streaming dan microwave. Kemudian menghaluskan zeolit, dengan cara ditumbuk lalu diayak dengan ukuran 100 mesh. Membuat adonan dan pencetakan pelet, komposisi adonan pelet yaitu $4 \%$ (4 gram) perekat, 42\% (42 gram) air mineral, dan 54\% (54 gram) zeolit dengan jumlah total yaitu 100 gram per adonan. Adonan yang telah jadi, kemudian diratakan menggunakan ampia hingga ketebalan $3 \mathrm{~mm}$ dan dicetak dengan diameter $10 \mathrm{~mm}$.
Setelah itu, melakukan pencetakan pelet yang sudah jadi, kemudian didiamkan selama 24 jam pada temperatur ruangan. Aktivasi pelet zeolit menggunakan microwave dengan daya pemanasan yaitu $80 \%, 60 \%$, dan $40 \%$, serta variasi waktu yaitu 3 menit, 6 menit dan 9 menit. Setelah dilakukan aktivasi, pelet dikemas menggunakan kawat streaming. Pengemasan ini bertujuan agar memudahkan pemasangan pelet pada filter udara sepeda motor. Wadah kemasan pelet memiliki ukuran yang sama dengan filter udara sepeda motor yang digunakan dalam penelitian. Pada saat pengemasan dilakukan penghitungan jumlah pelet, dimana jumlah pelet saat wadah penuh yaitu sebanyak 104 butir. Pada penelitian ini menggunakan variasi jumlah pelet 100\% (104 butir), 75\% (78 butir), dan 50\% (52 butir).

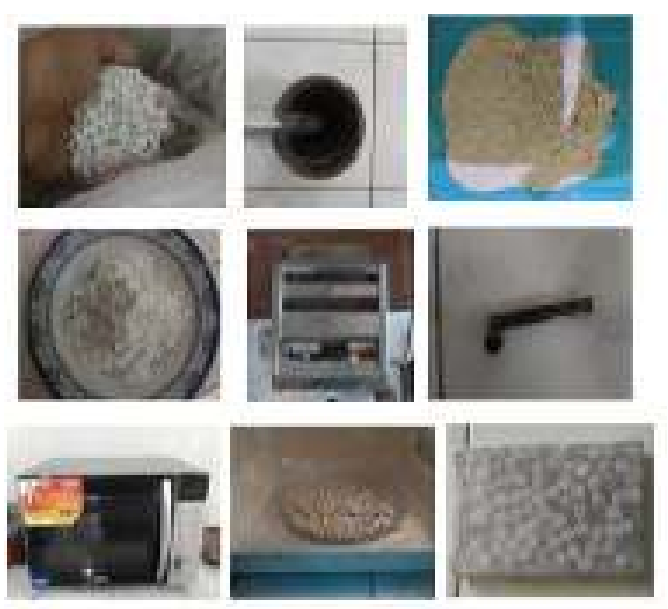

Gambar 1. Proses pembuatan filter zeolit

\section{Kendaraan Uji}

Penelitain ini menggunakan sepeda motor jenis Honda Beat dengan kapasitas mesin $108 \mathrm{cc}$

Sebelum dilakukan pengujian kendaraan uji di tune up supaya pada saat dialakukan pengujian kendaraan dalam peforma terbaik, agar diperoleh hasil terbaik pada saat pengujian. Selain itu kendaraan uji juga dipasang tachometer untuk mengetahui putaran mesin kendaraan uji. 


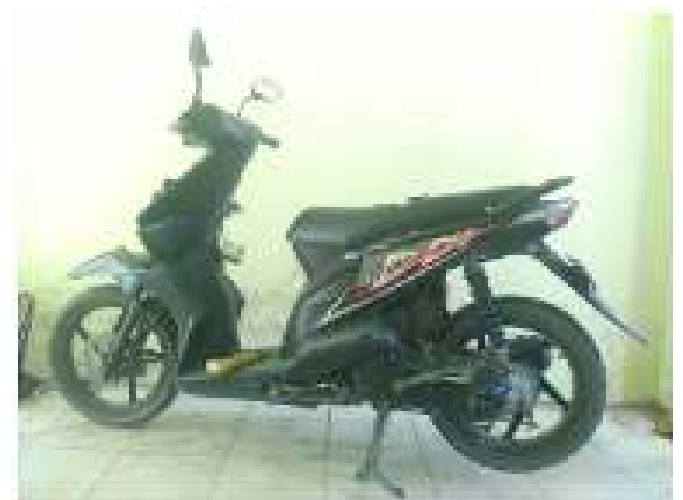

Gambar 2. Kendaraan uji

\section{Prosedur Pengujian}

Pengujian akselerasi bertujuan untuk mengetahui berapa waktu yang dibutuhkan kendaraan tersebut dari berhenti sampai berjalan hingga mencapai kecepatan yang diinginkan. Pengujian akselerasi dilakukan dari kecepatan 0-80 km/jam menggunakan filter buatan (filter zeolit). Pada pengujian akselerasi memerlukan track dengan panjang 150-200 m. Sebelum melakukan pengujian akselerasi siapkan tangki bahan bakar buatan, bahan bakar, dan filter zeolit.

Mesin motor dipanaskan sebelum dilakukan pengujian agar diperoleh kondisi mesin yang sama pada saat pengujian, setelah pemanasan selesai, mesin dimatikan. Selanjutnya dilakukan pemasangan filter (filter standar dan filter zeolit). Sepeda motor disiapakan pada track yang telah ditentukan. Selanjutnya hidupkan, ketika handle gas ditarik (kecepatan nol) saat bersamaan hidupkan stopwatch ketika gas ditarik sampai full lalu hidupkan stoptwacth. Setelah mencapai kecepatan yang diinginkan $(80 \mathrm{~km} / \mathrm{jam})$ pada speedometer stopwatch dimatikan. Catat waktu yang tertera pada stopwatch. Pada setiap pengujianya pengendara menarik gas full dari awal agar diperoleh tarikan gas yang sama untuk setiap pengujianya. Langkah-langkah tersebut diulangi 3 kali setiap pengujian filter zeolit maupun tidak menggunakan filter zeolit.
Pada pengujian awal hanya kerapatan pelet $75 \%$, dengan daya $80 \%$, waktu aktivasi 3,6 dan 9 menit. Selanjutnya pengujian dilakukan pada waktu aktivasi 6 menit dengan variasi daya $40 \%$, 60\% dan $80 \%$, serta menggunakan kerapatan (variasi jumlah pelet zeolit 100\%, $75 \%$ dan 50\% (untuk mengetahui perbedaaan pengaruh variasi kerapatan terhadap waktu tempuh akselerasi mesin sepeda motor). Sebelum dilakukan pengujian, mesin dipanaskan beberapa menit agar diperoleh kondisi yang sama pada saat pengujian

\section{HASIL DAN PEMBAHASAN}

Pengujian waktu tempuh (akselerasi) dilakukan untuk mengetahui pengaruh waktu dan daya aktivasi filter zeolit menggunakan microwave, serta pengaruh kerapatan pelet zeolit terhadap waktu tempuh akselerasi (0-80 $\mathrm{km} / \mathrm{jam})$ sepeda motor 4 langkah. Gambar 3 merupakan data pengujian waktu tempuh akselerasi yang telah dilakukan.

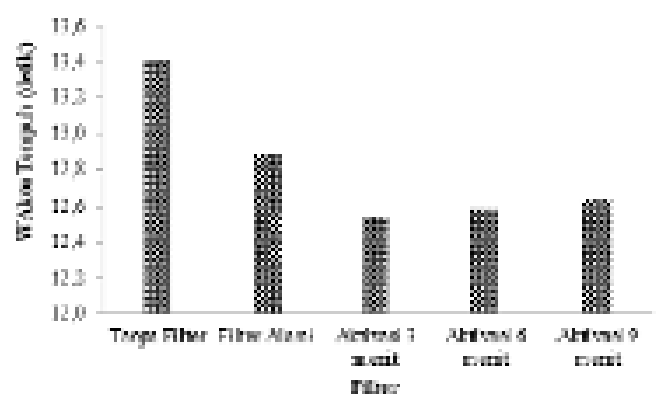

Gambar 3. Pengaruh waktu aktivasi filter zeolit terhadap waktu tempuh akselerasi

Penggunaan filter zeolit terbukti mampu memangkas waktu tempuh kendaraan dibandingkan dengan tanpa filter zeolit. Filter zeolit pada pengujian waktu tempuh terbukti mampu meningkatkan tenaga kendaraan sehingga mampu mempersingkat waktu tempuh seperti terlihat pada gambar 3. Pada saat tidak menggunakan filter zeolit, waktu tempuh rata-ratanya sebesar 13,42 detik. Kemudian filter dengan kemampuan terbaik yaitu filter aktivasi 3 menit dengan waktu tempuh rata-rata sebesar 12,54 detik, lebih cepat $6,53 \%$. Sementara itu, waktu aktivasi 6 menit dengan waktu tempuh rata-rata 12,58 
detik lebih cepat $6,19 \%$ dibandingkan tanpa filter zeolit. Selain itu, untuk filter dengan waktu aktivasi 9 menit diperoleh rata-rata waktu tempuh sebesar sebesar 12,63 detik, lebih cepat $5,81 \%$ dibandingkan dengan tanpa menggunakan filter zeolit.

Penggunaan filter alami juga memberikan penurunan waktu tempuh akselerasi dibandingkan dengan aktivasi 3 menit dan 6 menit. Filter alami mampu meningkatkan waktu tempuh sebesar 4,05\% dibandingkan tanpa filter zeolit. Kekuatan absorbsi pada zeolit teraktivasi fisik lebih baik dibandingkan zeolit alami [4].

Filter zeolit pada pengujian akselerasi terbukti mampu meningkatkan tenaga kendaraan sehingga mampu mempersingkat waktu tempuh. Hal itu dikarenakan pada saat udara akan masuk ke dalam ruang bakar tersaring filter zeolit sehingga uap air dan nitrogen tidak masuk ke dalam ruang bakar. Hal tersebut membuat pembakaran lebih sempurna sehingga meningkatkan tenaga mesin. Selanjutnya dilakukan pengujian menggunakan filter waktu aktivasi 6 menit dengan variasi daya $40 \%$, $60 \%$ dan $80 \%$, untuk mendapatkan daya terbaik, serta menggunakan jumlah pelet zeolit $100 \%, 75 \%$ dan $50 \%$ (untuk mengetahui perbedaaan pengaruh kerapatan terhadap waktu tempuh akselerasi mesin sepeda motor).

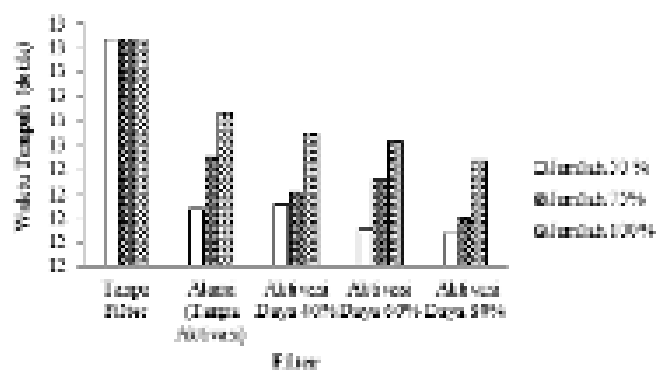

Gambar 4. Pengaruh daya aktivasi dan kerapatan filter zeolit terhadap waktu tempuh akselerasi

Daya aktivasi zeolit berpengaruh terhadap waktu tempuh kendaraan uji. Semakin besar daya aktivasi maka waktu tempuh sepeda motor semakin cepat. Hal ini dikarenakan proses aktivasi fisik mampu membuka poripori permukaan zeolit, sehingga zeolit menjadi adsorben yang baik. Dari gambar 4 dapat dilihat daya terbaik pada saat pengujian akselerasi yaitu daya $80 \%$. Pada pengujian waktu tempuh filter kerapatan 50\% mampu mendominasi menjadi yang terbaik dibandingkan dengan filter dengan kerapatan $75 \%$ dan $100 \%$.

Hal tersebut dikarenakan pada susunan pelet renggang memiliki hambatan udara lebih kecil dibandingkan dengan susunan pelet rapat. Kemudian kualitas udara yang masuk ruang bakar lebih baik dibandingkan dengan kondisi tanpa zeolit [4]. Selain itu, filter zeolit dengan susunan pelet renggang mampu meningkatkan waktu tempuh, lebih baik dibandingkan dengan susunan pelet rapat [1].

Filter yang mempunyai kemampuan peningkatan waktu tempuh pertama yaitu filter dengan kerapatan $50 \%$ dan daya $80 \%$ menghasilkan rata-rata waktu tempuh a sebesar 12,14 detik lebih cepat $6,16 \%$ dibandingkan tidak menggunakan filter zeolit, filter dengan kemampuan terbaik kedua yaitu pada daya $60 \%$ kerapatan $50 \%$, rata rata waktu tempuh sebesar 12,15 detik, lebih cepat $6,06 \%$ dibandingkan tanpa filter zeolit.

Filter dengan kemampuan terbaik ketiga yaitu filter dengan daya $80 \%$ kerapatan $75 \%$, ratarata waktu tempuh akselerasi sebesar 12,21detik, lebih cepat 5,64\% dibandingkan tanpa filter zeolit. Selain itu, filter alami dengan kerapatan 100\% mampu meningkatkan waktu tempuh akselerasi sebesar 2,34\% dibandingkan dengan tanpa filter. Penggunaan filter zeolit terbukti mampu meningkatkan tenaga kendaraan, karena filter zeolit mampu menyerap uap air dan $\mathrm{N}_{2}$ sehingga okigen yang masuk keruang bakar lebih banyak atau pembakaran yang kaya oksigen. sehingga membuat pembakaran lebih sempurna.

\section{KESIMPULAN}

Waktu dan daya aktivasi berpengaruhi terhadap akselerasi sepeda motor. Waktu aktivasi yang lama dapat menyebabkan 
penurunkan akselerasi. Kemudian, semakin besar daya aktivasi maka semakin meningkatkan akselerasi sepeda motor. Sementara itu, susunan pelet renggang mampu meningkatkan akselerasi, lebih baik dibandingkan dengan susunan pelet rapat.

\section{DAFTAR PUSTAKA}

[1] Apriliando, E.S. 2017. Penggunaan Fly Ash Dan Zeolit Untuk Menghemat Bahan Bakar Dan Mereduksi Emisi Gas Buang Sepeda Motor Bensin 4-Langkah. Skripsi Jurusan Teknik Mesin-Universitas Lampung : Bandar Lampung.

[2] Ernadi, A. 2017. Pemanfaatan Campuran Zeolit Alam-Fly Ash Batu Bara Yang telah dikativasi Fisik Untuk Meningkatkan Prestasi Mesin Bensin 4-Langkah. Skripsi Jurusan Teknik Mesin-Universitas Lampung : Bandar Lampung.

[3] Ismiyati, S.D. 2015. Pengaruh Aktivasi Terhadap Zeolit Alam Lampung Sebagai Adsorben GAS CO2 Dari Biogas. Jurnal Lembaga Penelitian dan Pengabdian Universitas Lampung. Bandar Lampung

[4] Priyadi, N. 2007. Pengaruh Pemenfaatan zeolit Alam Lampung Yang Diaktivasi Fisik Terhadap Prestasi Mesin Mobil Dengan Sistem Elektrik Fuel Injektion (EFI) 1600 cc. Skripsi Jurusan Teknik Mesin-Universitas Lampung : Bandar Lampung.

[5] Tans, P. \& K. Thoning. 2018. Mole Fraction in Dry Air. NOAA Earth System Research Laboratory Global Monitoring Division. Colorado. $8 \mathrm{Pp}$.

[6] Wardono, H. 2004. Modul Pembelajaran Motor Bakar. Jurusan Teknik Mesin. Universitas Lampung. Bandar Lampung. 